\title{
BMJ Open Strategies occupational therapists employ to facilitate work-related transitions for persons with hand injuries: a study protocol for a scoping review
}

\author{
Michelle Elizabeth Uys, ${ }^{\oplus, 2}$ Helen Buchanan, ${ }^{3}$ Lana Van Niekerk ${ }^{1}$
}

To cite: Uys ME, Buchanan $\mathrm{H}$, Van Niekerk L. Strategies occupational therapists employ to facilitate work-related transitions for persons with hand injuries: a study protocol for a scoping review. BMJ Open 2019;9:e027402. doi:10.1136/ bmjopen-2018-027402

- Prepublication history for this paper is available online. To view these files please visit the journal online (http://dx.doi org/10.1136/bmjopen-2018027402).

Received 20 0ctober 2018 Revised 21 February 2019 Accepted 28 February 2019

Check for updates

(c) Author(s) (or their employer(s)) 2019. Re-use permitted under CC BY-NC. No commercial re-use. See rights and permissions. Published by BMJ.

${ }^{1}$ Occupational Therapy, Stellenbosch University Department of Medicine, Cape Town, South Africa

${ }^{2}$ Occupational Therapy, University of Cape Town Department of Health and Rehabilitation, Cape Town, Western Cape, South Africa ${ }^{3}$ Health \& Rehabilitation Sciences, University of Cape Town Faculty of Health Sciences, Observatory, South Africa

Correspondence to Miss Michelle Elizabeth Uys; michelleelizabethuys@gmail. com

\section{ABSTRACT}

Introduction Hands make it possible to be employable and productive, to communicate non-verbally and to perform fine motor tasks required in day-to-day activities. Sustaining a hand injury can be detrimental to function including the ability to work. As the literature on workrelated transitions is scattered across a range of journals, it is difficult to get a sense of how much literature there is, what is known and where the gaps lie. This scoping study will provide a single source of up-to-date evidence to inform health professionals about the strategies occupational therapists employ to facilitate work-related transitions for people with hand injuries.

Methods and analysis The methodological framework by Arksey and 0'Malley (2005) will form the structure of the scoping review. The search strategy has been developed in collaboration with a subject librarian. The following databases will be searched: EBSCOhost including only Medline, CINAHL and Health Source: Nursing/Academic Edition; PubMed, Scopus, The Cochrane library and Web of Science. Reference lists will be examined, and grey literature sources will be searched to ensure that literature missed in the database searches is included. Covidence will be used to manage the project. Full-texts will be uploaded for literature that meets the inclusion criteria. A process of blind review will be used to ensure that consistency and rigour is upheld.

Ethics and dissemination The findings of the scoping review will be disseminated in an article, within 2019, to be published in a peer-reviewed journal. The findings will be presented at conferences to ensure the optimal dissemination of the scoping review's conclusions.

\section{INTRODUCTION}

\section{Background to the problem}

Hands are essential for the optimal completion of functional tasks that people do on a daily basis. Hands support employability, productivity, communication, balance and manipulation of tools and other fine motor tasks in day-to-day activities. ${ }^{1} \mathrm{~A}$ hand injury causes substantial occupational disruption temporarily preventing engagement in
Strengths and limitations of this study

- The search strategy for this scoping review protocol has been developed comprehensively in collaboration with an expert librarian who verified the search terms and database choices to be used.

- The search strategy will include databases (PubMed, Scopus, Web of Science, Cochrane, Medline, CINAHL and Health Source: Nursing/Academic Edition) reference lists and grey literature sources to ensure that all applicable literature is captured.

- The researchers will conduct a blind review to ensure rigorous and consistent application of the inclusion and exclusion criteria.

- A codebook system, such as "R" qualitative data analysis (RQDA), will be used to analyse the literature to maximise the findings in terms of both implications for clinical practice and research.

- The scoping review will be limited to occupational therapists and will therefore not include literature by other professions who may be publishing within the field of work transitions and hand injuries.

activities of daily living, including work. The disruption is temporary while the person receives rehabilitation to restore functional components or makes adaptations where function cannot be restored. ${ }^{2} \mathrm{~A}$ variety of possible work-related outcomes are possible ranging from returning to the same job in the same capacity to having to find alternative employment. Adaptations tend to be slow and require the integration of both physical and psychosocial components. ${ }^{3}$

Despite the hand injury being physical, it can impact on an individual's self-perception and emotional well-being. It has also been suggested that the barriers in work-related transitions include the interplay between personal, work or family related problems rather than that of the hand injury. ${ }^{4}$ Deeprooted fears and insecurities can frequently 
manifest in physically injured employees, as they perceive themselves as inadequate, unable to fulfil their job role optimally or develop a genuine fear of job loss. ${ }^{5}$ Hand injuries typically require extensive rehabilitation over time, and the extended recovery process may keep a person out of work. Occupational therapists fulfil an essential role in restoring hand function and participation in daily activities. This is through the use of specialised treatment techniques, approaches and modalities, in addition to having a unique focus on return to work and adaptations within the workplace. ${ }^{6}$ Rehabilitation is, however, restricted by the budgets available in the healthcare sector. ${ }^{7}$

Disability, which may be caused by impairments due to hand injuries, has been linked to poverty as the hand injury affects the persons' ability to work. ${ }^{8}$ Therefore, disability due to a hand injury may expose individuals and their families to the risk of becoming impoverished. This is particularly devastating in low- and middle-income countries, as a large percentage of people are not formally employed. Individuals with impairments and disabilities who operate in the informal economy, frequently have difficulties re-entering the workplace. If a worker is unable to perform his or her work tasks and there are no alternative jobs within the organisation, he or she may lose his or her work where the likelihood of re-employment is poor. This is critical in low- and middle-income countries where unemployment is rife. For example, in South Africa, a middle-income country, unemployment rates are estimated to be $27.7 \%$ of the population, amounting to 6.08 million people. ${ }^{9}$

Gosselin found that injuries were the leading cause of disability and death world-wide, in people under the age of $60 .{ }^{10}$ Over 5 million people die every year from injuries, of which over $90 \%$ of these deaths occur in low- and middle-income countries. ${ }^{10}$ Hand injuries are a common reason for persons requiring vocational rehabilitation and/or occupational therapy intervention. In a study conducted from 2004 to 2006, it was established that $23.4 \%$ of people in Hong Kong who was referred to occupational therapy for work rehabilitation $(n=3031)$, had sustained upper limb injuries. ${ }^{11}$ In the USA, the total cost of injuries involving the upper limb in 2004, has been estimated at approximately $\$ 19$ billion and accounts for one-third of all injuries in the country. ${ }^{12}$ The costs incurred due to the loss of productivity after sustaining a hand injury are estimated to be double that of the healthcare costs. ${ }^{13}$ The subsequent economic burden of absenteeism, in addition to the healthcare costs incurred due to a hand injury, requires researchers and policymakers to understand it intricately well. The global burden of injury predominantly falls within low- and middle-income countries. In a 2008 paper by Spiegel et al it was reported that 'addressing the burden of injury in low- and middle-income countries has become a public health priority'. ${ }^{14}$

Work-related transitions of clients with hand injuries is a growing field within occupational therapy. Scoping reviews are appropriate when the available literature is extensive, multifaceted or heterogeneous. ${ }^{15}$ The literature on work-related transitions after sustaining a hand injury is scattered across different professions and journals, which makes it difficult to get a sense of how much literature there is, what is known and where the gaps lie. Treatment of hand injuries may involve a variety of health professions, each of whom play a role in the overall rehabilitation process. Occupational therapists have a unique role in treating clients with a hand injury as their treatment goals are aligned specifically with return to work and workplace adaptations, in addition to treating their clients' hand injury. This scoping review will map the existing literature pertaining to occupational therapy and work transitions to inform a national survey to be conducted in South Africa on the subject.

\section{Background to the literature}

It is clear that developing countries have complex and diverse social, organisational, political and infrastructural challenges that need to be explored within a specific context. This is primarily due to the interplay between education, socio-economic status, multi-disciplinary healthcare intervention and work-related transition coordination. ${ }^{12}$ In Brazil, the need to improve occupational therapists' understanding of the work-related transition process regarding factors such as increased healthcare costs and low levels of employment for individuals with disabilities was highlighted. ${ }^{16}$ The healthcare system in South Africa is divided along socio-economic lines, whereby people who are in a higher income bracket can buy health insurance which affords them more efficient healthcare services, better resources and reduced waiting times. ${ }^{17}$ There are also low-income countries, who only have government healthcare options and some who have no allied healthcare professionals trained or working within these countries at all.

In Shi et $a l$ 's systematic review, education and income appeared to be significant factors in the length of time taken to transition to work. ${ }^{18}$ Shi $e t$ al, also found that income affected duration to return to work, wherein Taiwan, people with better education and those with a higher income were found to be 6.5 times more likely to return to work. ${ }^{19}$ In the Netherlands, it was found that the expectations of white-collar employees' return to work were 4.3 times higher than that of manual labourers. ${ }^{13}$ In Denmark, age, gender and social variables did not significantly influence absenteeism from work. ${ }^{19}$ It is not clear whether low- or middle-income countries will document the same findings as those reported in high-income countries. This emphasises the need to gain clarity on context-specific work-related transition strategies used by occupational therapists classified as low-, middle- and high-income countries, according to the World Bank.

Hand injuries are the primary cause of work-related disability in young employees throughout the UK. ${ }^{8}$ Sustaining a hand injury is frequently unforeseen, which complicates the work-related transition process, as the individual will typically have limited time to prepare and adjust to the hand injury. Ammann et al (2014) reported 
that hand injuries were responsible for occupational disruptions, changes in occupational patterns and occupational limitations, which requires adaptations and creates immense challenges in a person's daily life. ${ }^{20}$ This is likely to include the successful work-related transition of the person with the hand injury. It was noted that when an injured worker has been absent from work for an extended amount of time, their transition in returning to work can be complicated by feelings of non-compliance with the demands of their job, feelings of inadequacy and feelings around a loss of control. ${ }^{5}$

Ramel $e t a l^{21}$ found that although most participants had returned to work $(67.5 \%)$, those who had not returned to work had higher perceived disability, reduced hand function and were more dissatisfied with their daily occupations than those who were back at work. ${ }^{21}$ In Brazil, a cross-sectional study $(n=35)$, found that the factors associated with work-related transitions after a hand injury, 3 years after discharge from rehabilitation, were grip strength, occupational performance scores, occupational category and age. ${ }^{16}$ The qualitative data revealed the complex nature of work-related transitions following a hand injury and indicated that professional input in specific areas probably contributed to successful work-related transitions. ${ }^{16}$ Self-perceived health has been shown to be an essential factor in successful work-related transitions following a traumatic work-related hand injury. ${ }^{11}$ Each of these studies contributed critical knowledge to the field of work-related transitions after a hand injury, however, few have identified the strategies that seemed to be most helpful in the context of a low-, middle- or high-income country. Therefore, we are aiming to identify what research has been conducted over the last decade (2008 to 2018) on the strategies occupational therapists employ to facilitate work-related transitions for people with hand injuries in low-, middle- and high-income countries.

\section{Aim and objectives}

This scoping review aims to identify research conducted in the last decade (2008 to 2018) on the strategies occupational therapists employ to facilitate work-related transitions for people with hand injuries. Objectives are:

- To identify the strategies used by occupational therapists to facilitate work-related transitions after hand injuries.

- To describe the different types of work-related transitions found in the literature.

- To determine which factors, contribute to work transitions and how these factors differ internationally.

\section{METHODS AND ANALYSIS}

The methodology that will be used in the proposed scoping review was informed by Peters et al and Colquhoun et al. ${ }^{1522}$ Arksey and O'Malley's, ${ }^{23}$ methodological framework will be used to guide the scoping review.

\section{Box 1 Methodological framework ${ }^{23}$}

Stage 1: identifying the research question

- Stage 2: identifying relevant studies

- Stage 3: study selection

- Stage 4: charting the data

Stage 5: collating, summarising and reporting the results

Box 1 depicts the stages of the scoping review process, each of which is described in more detail in the subsequent sections.

\section{Stage 1: identifying the research question}

Broad research questions were developed to ensure that the scoping review would not lend itself to the exclusive identification of particular types of studies, but would capture the diversity and scope of the literature available. $^{1523}$

The research questions are:

1. What strategies do occupational therapists use to facilitate work-related transitions after hand injuries?

2. What types of work-related transitions are described in the literature?

3. What factors contribute to transitions to work and how do they differ internationally?

\section{Stage 2: study identification}

The search will identify literature from electronic databases. Additional hand searches will be conducted to assist in retrieving literature missed in the database searches. ${ }^{23}$ The reference lists of the included articles will be searched to ensure that all relevant literature is included. Saturation is considered to be the point at which no new literature is found to be included in the scoping review.

The following databases have been selected in consultation with a subject librarian: EBSCOhost (including Medline, CINAHL and Health Source: Nursing/ Academic Edition). The databases were chosen to ensure that all relevant literature was identified. An initial, limited search selection of relevant databases will take place, followed by an analysis of text words in the title and abstract, as well as the index terms used to describe the article.

A Boolean search string has been developed through the systematic process of reviewing Medical Subject Heading terms on Medline. In consultation with the subject librarian, the initial search terms have been developed for each database (see table 1).

An initial screening has been run to avoid using broad searches that would result in an unmanageably large number of results. ${ }^{23}$ The results for the initial screening run using the abstract/title field are presented in table 2 below. The cut-off date applied for the search strategy screening was 30 August 2018.

To ensure that all relevant studies are included, additional, peer-reviewed literature will be added by hand 
Table 1 Search strategy derived from the medical subject heading terms

TOPIC: $\quad$ Hand OR hands OR 'Upper Extremity' OR 'upper limb'

AND TOPIC: 'Return to Work' OR 'return-to-work' OR 'work transition' OR 'back to work' OR 'back-to-work'

AND TOPIC: $\quad$ occup* AND (therap* OR rehab*)

searching the reference lists of the articles that were initially included to ensure that articles have not been missed.

\section{Stage 3: study selection}

It is not considered necessary to place strict limitations on search terms, the identification of literature and the study selection at the outset of the scoping review protocol, as increased familiarity with the available literature will guide an iterative research process. ${ }^{23}$ There will be no restrictions by country or language for the initial screening.

Studies published within the last decade (2008 to 2018) will be included in the review. Limitations will, however, include the additional, database specific filters that were implied, namely timespan, age groups, articles only and the specific indexes on the Web of Science database. This is due to the unmanageably large search results obtained without the appropriate filters used.

Preliminary inclusion and exclusion criteria have been drafted as a general guideline to select studies for the review (see table 3). Unlike systematic reviews, the inclusion criteria are not focused on the quality of the research produced. ${ }^{24}$ Therefore, all studies that meet the inclusion criteria will be included regardless of the quality and rigour of the study. The study selection process will exclude literature on polytrauma, as the transition to work may differ on account of other injuries, and therefore not the hand injury specifically. This will also ensure that the primary focus of the intervention in the article will be for hand injuries. Furthermore, conference abstracts on work related transitions after a hand injury will also be excluded as detailed literature is required for the 'descriptive-analytical' method of analysis that will be used in this study.

In consultation with a librarian, databases and search strategies will be determined. All literature will be uploaded onto the Covidence platform to manage the project. Covidence will automatically remove and highlight duplicates, before the start of the review process. Covidence will initially be used to upload the abstracts and titles captured in the initial screening. The second and third authors will blind review all captured literature

\begin{tabular}{ll}
\hline Table 2 Initial database screening results & \\
\hline EBSCOhost including only Medline, CINAHL and & \\
Health Source: Nursing/Academic Edition & 77 \\
Pubmed & 99 \\
Scopus & 53 \\
The Cochrane Library & 15 \\
Web of Science & 67 \\
\hline
\end{tabular}

to determine its eligibility for selection into the scoping review. Where consensus is not achieved, another reviewer will be involved in debating any disagreements until a consensus is reached.

Full-texts will be uploaded for articles that meet the inclusion criteria. The researchers have set parameters to ensure that only published manuscripts and doctoral theses will be included in the scoping review. This will identify any systematic or literature reviews that have yet to be included through the initial searches. Grey literature will be identified by using the WHO's OpenGrey and OpenDOAR Library, as well as sources such as Open Access Theses and Dissertations, Sabinet: Current and Completed Research, ProQuest Dissertations and Theses, Database of African Theses and Dissertations and the Networked Digital Library of Theses and Dissertations to include doctoral research conducted by occupational therapists.

The Preferred Reporting Items for Systematic Reviews and Meta-analyses Protocols (PRISMA-P) flow diagram will be used to document the search and identification of studies. The number of studies identified in each step of the study selection process will be documented to represent

Table 3 Provisional selection Criterion

\begin{tabular}{ll}
\hline Inclusion criteria & Exclusion criteria \\
\hline $\begin{array}{l}\text { Literature on hand, upper } \\
\text { limb or upper extremity } \\
\text { injuries and return to work } \\
\text { or work transition. }\end{array}$ & $\begin{array}{l}\text { Literature on polytrauma which } \\
\text { includes the hand, upper limb } \\
\text { or upper extremity injuries and } \\
\text { successful return to work or } \\
\text { successful work transition. }\end{array}$ \\
$\begin{array}{l}\text { Studies with adults (aged } \\
18 \text { to 65years) who }\end{array}$ & $\begin{array}{l}\text { Conference abstracts on work- } \\
\text { related transitions after a hand } \\
\text { are working within the } \\
\text { open labour market or in }\end{array}$ \\
$\begin{array}{l}\text { sheltered employment. } \\
\text { Studies involving }\end{array}$ \\
$\begin{array}{l}\text { participants with a variety } \\
\text { of possible work-related } \\
\text { outcomes ranging from } \\
\text { returning to the same job } \\
\text { in the same capacity to } \\
\text { having to find alternative } \\
\text { employment. }\end{array}$ \\
$\begin{array}{l}\text { At least one author must be } \\
\text { an occupational therapist } \\
\text { or the intervention in the } \\
\text { article must directly refer to } \\
\text { those used by occupational } \\
\text { therapists. }\end{array}$ \\
\hline
\end{tabular}


the process visually. The PRISMA-P flow diagram will assist with reporting the duplicates found between the databases.

\section{Stage 4: charting the data}

The 'descriptive-analytical' method will ensure that the authors collect standard information that will be useful to disseminate the findings in a concise and user-friendly format. ${ }^{2}$ The 'descriptive-analytical' approach will assist the researchers to: identify historical data that will answer the research question comprehensively, to organise existing literature and to identify significant patterns and links within the literature. Care will be taken when charting the data, to ensure that accuracy is maintained. ${ }^{25}$

A qualitative data analysis system, such as the "R" qualitative data analysis (RQDA) program, will be used to analyse and categorise literature into theme areas. RQDA is a qualitative data analysis tool which makes use of computer assisted qualitative data analysis software to facilitate the process. ${ }^{26}$ The codebook will be used to identify the strategies occupational therapists use to facilitate the work transitions for clients who have sustained hand injuries. To conduct a narrative on the available literature, the primary researcher will identify sub-themes from the sources included in the scoping review. The researchers will then critically analyse the sub-themes to identify the themes that will be discussed in the results section of the scoping review. The researchers will be cognisant of implications for practice and research when identifying themes. ${ }^{27}$ Before grouping the barriers experienced by clients with hand injuries by country classification, the barriers will be described. The barriers will also be tabulated according to the World Bank classification of low-, middle- and high-income countries. This will assist in identifying gaps in the existing literature, as it is likely that there will be more literature from the global north than that produced by lowand/or middle-income countries.

The following general information will be extracted and tabulated from the included articles: author name(s), publishing journal, year of publication, country of origin, study population, the study aims/objectives/question, the setting, study-design and findings. In addition, themes will be extracted from the following areas:

the strategies occupational therapists used to enable work-related transitions;

the types of work-related transitions described and,

the factors that contribute to transitions to work classi-

fied by World Bank country income groupings.

\section{Stage 5: collating, summarising and reporting the results}

A descriptive and narrative summary of the study findings will be presented. Summary tables will be used to portray the vital elements of each study whether qualitative, quantitative or mixed methods approaches have been used.

To determine what literature has been produced over the last decade, we will tabulate a list of countries and sources from which research or literature about hand injuries and work-related transitions has been conducted. We will further provide a percentage breakdown of
Table 4 Study timeline

The research questions have been formulated to develop the scoping review protocol and to initiate the Stage 1: identifying planning of the scoping review to the research question follow.

$\begin{array}{ll}\begin{array}{l}\text { Stage 2: identifying } \\ \text { relevant studies }\end{array} & \begin{array}{l}\text { The databases and search strategy } \\ \text { have been determined in consultation } \\ \text { with a subject librarian. An initial } \\ \text { search has been run. However, the } \\ \text { identification of relevant studies is } \\ \text { still being confirmed. }\end{array}\end{array}$

Stage 3: study

selection

A provisional inclusion and exclusion criteria have been formulated. However, this process is iterative and is therefore likely to change once the scoping review commences. We expect that roughly 132 articles will be screened after duplicates have been removed. The researchers will review 22 titles and abstracts per day over six working days. Once the included literature has been selected and the additional grey and hand searched literature has been included, the full-texts will be reviewed. The researchers are aiming to review 11 full-texts per day, which will amount to 12 working days. The total amount of time for data collection of the scoping review is expected to be approximately 30 working days.

$\begin{array}{ll}\begin{array}{l}\text { Stage 4: charting the } \\ \text { data }\end{array} & \begin{array}{l}\text { The data will be charted once stage } \\ \text { three has been completed in entirety. } \\ \text { The researchers have allocated } \\ 21 \text { working days to conduct the } \\ \text { descriptive analysis and to tabulate } \\ \text { all the research findings. }\end{array} \\ \text { Stage 5: collating, } & \begin{array}{l}\text { Once stage } 4 \text { has been completed, } \\ \text { summarising and } \\ \text { reporting the results } 5 \text { will be initiated. A descriptive } \\ \text { and a narrative summary of the study } \\ \text { findings will be presented and written } \\ \text { up into an article. The scoping review } \\ \text { findings will be written up into an } \\ \text { article in the first } 6 \text { months of } 2019, \text { to } \\ \text { ensure optimal dissemination of the } \\ \text { findings. }\end{array} \\ \end{array}$

literature published by World Bank country classification, namely low-, middle- and high-income.

From the literature included in the scoping review, key quotes and ideas will be extrapolated to describe work-related transitions. The findings will be synthesised into a coherent article with applications to research and clinical practice.

\section{Study timeline}

The proposed details pertaining to the study timeline are described in table 4. 


\section{Patient and public involvement}

The scoping review to follow on this protocol, will not require the participation of any patients or the general public.

\section{DISCUSSION (ETHICS AND DISSEMINATION)}

Because the literature on this topic is scattered across a range of journals, it is challenging to determine how much literature there is, what is known and where the gaps lie. A scoping review will be beneficial in examining the extent of available literature, identifying possible research gaps and in synthesising the findings. This will take place once all the steps in the scoping review process have been completed. The researchers anticipate that the findings of this scoping review will have an application in research, policy development as well as in a clinical context and will be written up for publication in an international peer-reviewed journal. The findings will also be presented at conferences. The proposed scoping review is feasible, realistic and can be done within the time allocated in the proposed timeline.

Ethics approval is not required for the scoping review, as existing literature will be analysed. Exploring the barriers in work-related transitions, in low- and middle-income countries, through the use of a scoping review, can assist occupational therapists and researchers who are addressing the obstacles within the system, to have an informed position. The scoping review protocol has assisted the researchers in consultation with a librarian, to cast the scope wide enough to obtain literature from lowand middle-income countries which can contextualise work-related transitions after sustaining a hand injury from the low-, middle- or high-income countries' perspective, which is the ultimate aim of this scoping review.

It is useful to determine the strategies employed by occupational therapists and the barriers that people who have sustained hand injuries experience according to the World Bank classification of countries, as the barriers and means for addressing them is likely to differ in various contexts. This is likely to be more beneficial for clinicians and researchers in identifying gaps and applications in their specific countries. Furthermore, contradictory findings during the initial screenings demonstrate the need to distinguish between low-, middle- and high-income countries.

Acknowledgements The authors acknowledge Mrs Ingrid Van der Westhuizen (subject librarian) at Stellenbosch University, for her assistance in developing the initial search terms for the scoping review. The authors would also like to acknowledge Mrs Theron (librarian), who assisted the researchers with the initial screenings and database use training. The financial assistance of the National Research Foundation (NRF) towards this research is hereby acknowledged. Opinions expressed and conclusions arrived at, are those of the author and are not necessarily to be attributed to the NRF.

Contributors All three authors conceptualised, drafted, developed and edited the protocol in preparation for the scoping review. MEU drafted the initial protocol manuscript as part of her master's degree. HB and LVN guided the protocol development and made numerous conceptual and editing contributions. All researchers contributed to all drafts of the manuscript and will be involved in screening and extracting the data once the scoping review commences. The researchers are all committed to being accountable for all aspects of this protocol.

Funding The authors have not declared a specific grant for this research from any funding agency in the public, commercial or not-for-profit sectors. The National Research Foundation (NRF) assisted towards funding this research publication.

Competing interests None declared.

Patient consent for publication Not required.

Provenance and peer review Not commissioned; externally peer reviewed.

Data sharing statement The papers that are to be included in the scoping review are uploaded onto Covidence. The project is password protected and is only accessed by the three researchers.

Open access This is an open access article distributed in accordance with the Creative Commons Attribution Non Commercial (CC BY-NC 4.0) license, which permits others to distribute, remix, adapt, build upon this work non-commercially, and license their derivative works on different terms, provided the original work is properly cited, appropriate credit is given, any changes made indicated, and the use is non-commercial. See: http://creativecommons.org/licenses/by-nc/4.0/.

\section{REFERENCES}

1. Bates E, Therapy RM-BJ. Coping Strategies Used by People with a Major Hand Injury: A Review of the Literature. journals.sagepub.com [Internet]. 2014 http://journals.sagepub.com/doi/abs/10.4276/0308 $02214 X 14018723137995$ (cited 1 Oct 2018).

2. Whiteford G. Occupational Deprivation: Global Challenge in the New Millennium. British Journal of Occupational Therapy 2000;63:200-4.

3. Chan J, Therapy JS-AJ. Adaptation to hand injury: an evolving experience. ajot.aota.org [Internet]. 2004 https://ajot.aota.org/ pdfaccess.ashx?url=/data/journals/ajot/930154/128.pdf (cited 1 Oct 2018).

4. Opsteegh L, Reinders-Messelink HA, Schollier D, et al. Determinants of return to work in patients with hand disorders and hand injuries. $J$ Occup Rehabil 2009;19:245-55.

5. Keough J, Work TF. Occupational-psychosocial perceptions influencing return to work and functional performance of injured workers. content.iospress.com [Internet]. $2001 \mathrm{https}: / /$ content. iospress.com/articles/work/wor00141 (cited 1 Oct 2018).

6. De KS, Badenhorst E. Occupation-based hand therapy in South Africa: challenges and opportunities. scielo.org.za [Internet]. 2016 http://www.scielo.org.za/scielo.php?pid=S2310$38332016000300003 \&$ script=sci_arttext\&tIng=es (cited 1 Oct 2018).

7. Seedat M, Van NA, Jewkes R, et al. Violence and injuries in South Africa: prioritising an agenda for prevention. Elsevier [Internet] 2009 https://www.sciencedirect.com/science/article/pii/ S014067360960948X (cited 1 Oct 2018).

8. Urso-Baiarda F, Lyons R, Laing JSB journal of, 2008 undefined. A prospective evaluation of the Modified Hand Injury Severity Score in predicting return to work. Elsevier [Internet]. https://www. sciencedirect.com/science/article/pii/S174391910700132X (cited 2018 Oct 1).

9. Trading Economics. South Africa Unemployment Rate | 2000-2018 | Data | Chart | Calendar [Internet]. https://tradingeconomics.com/ south-africa/unemployment-rate (cited 1 Oct 2018).

10. Gosselin RA. The Increasing Burden of Injuries in Developing Countries. Techniques in Orthopaedics 2009;24:230-2.

11. Cheng ASK, Cheng SWC. Use of job-specific functional capacity evaluation to predict the return to work of patients with a distal radius fracture. American Journal of Occupational Therapy 2011;65:445-52 ajot.aota.org [Internet]https://ajot.aota.org/article.aspx?articleid= 1851491.

12. Cancelliere C, Donovan J, Stochkendahl MJ, et al. Factors affecting return to work after injury or illness: best evidence synthesis of systematic reviews. Chiropr Man Therap 2016;24:32.

13. Ruijs A, Jaquet J, Giele H, et al. The road to optimized nerve reconstruction [Internet]. 2005 https://pdfs.semanticscholar.org/ bbdb/5e26d67a72d70f2ec2853584d0b65395aeec.pdf\#page=27 (cited 1 Oct 2018).

14. Spiegel DA, Gosselin RA, Coughlin RR, et al. The burden of musculoskeletal injury in low and middle-income countries: challenges and opportunities. J Bone Joint Surg Am 2008;90:915-23.

15. Peters MD, Godfrey $\mathrm{CM}$, Khalil $\mathrm{H}$, et al. Guidance for conducting systematic scoping reviews. Int J Evid Based Healthc 2015;13:141-6.

16. Cabral L, Sampaio R. IF-BJ of, 2010 undefined. Factors associated with return to work following a hand injury: a qualitative/quantitative approach. SciELO Bras [Internet]. 2010 http://www.scielo.br/scielo. 
php?pid=S1413-35552010005000004\&script=sci_arttext (cited 1 Oct 2018).

17. Young M. Private vs Public Healthcare in South Africa. $2016 \mathrm{http}: / /$ scholarworks.wmich.edu/honors_theses/2741/ (cited 1 Oct 2018).

18. Shi Q, Sinden K, MacDermid JC, et al. A systematic review of prognostic factors for return to work following work-related traumatic hand injury. J Hand Ther 2014;27:55-62.

19. Skov O, Jeune B, Lauritsen JM, et al. Time off work after occupational hand injuries. J Hand Surg Br 1999;24:187-9.

20. Ammann B, Satink T, Therapy MA-H. Experiencing occupations with chronic hand disability: narratives of hand-injured adults. journals. sagepub.com [Internet]. 2012 http://journals.sagepub.com/doi/abs/ (cited 1 Oct 2018).

21. Ramel E, Rosberg H, Dahlin L, et al. Return to work after a serious hand injury. content.iospress.com [Internet]. 2013 https://content. iospress.com/articles/work/wor01373 (cited 1 Oct 2018).
22. Colquhoun $\mathrm{HL}$, Jesus TS, O'Brien $\mathrm{KK}$, et al. Study protocol for a scoping review on rehabilitation scoping reviews. Clin Rehabil 2017;31:1249-56.

23. Arksey H. Scoping studies: towards a methodological framework. Taylor Fr [Internet]. https://www.tandfonline.com/doi/abs/10.1080/ 1364557032000119616 (cited 1 Oct 2018).

24. Tricco AC, Lillie E, Zarin W, et al. A scoping review on the conduct and reporting of scoping reviews. BMC Med Res Methodol 2016;16:15

25. Peterson J, Pearce PF, Ferguson LA, et al. Understanding scoping reviews. J Am Assoc Nurse Pract 2017;29:12-16.

26. Chandra Y, Shang L. An RQDA-based constructivist methodology for qualitative research. Qualitative Market Research: An International Journal 2017;20:90-112.

27. Capri C, Abrahams L. Intellectual disability rights and inclusive citizenship in South Africa: What can a scoping review tell us? ncbi. nlm.nih.gov [Internet]. 2018 https://www.ncbi.nlm.nih.gov/pmc/ articles/PMC5968870/ (cited 1 Oct 2018). 
Correction: Strategies occupational therapists employ to facilitate work-related transitions for persons with hand injuries: a study protocol for a scoping review

Uys ME, Buchanan H, Van Niekerk L. Strategies occupational therapists employ to facilitate work-related transitions for persons with hand injuries: a study protocol for a scoping review. BMJ Open 2019;9:e027402. doi: 10.1136/bmjopen-2018-027402

This article was previously published with the incorrect reference.

De KS, Badenhorst E. Occupation-based hand therapy in South Africa: challenges and opportunities. scielo.org.za [Internet]. 2016 http://www.scielo.org.za/scielo.php?pid= S2310-38332016000300003\&script=sci_arttext\&tlng=es (cited 1 Oct 2018).

Now, the reference has been revised as given below:

De Klerk S, Badenhorst E, Buttle A, et al. Occupation based hand therapy in the South African context: challenges and opportunities. S AfrJ Occup Ther 2016;46:10-4.

Open access This is an open access article distributed in accordance with the Creative Commons Attribution Non Commercial (CC BY-NC 4.0) license, which permits others to distribute, remix, adapt, build upon this work non-commercially, and license their derivative works on different terms, provided the original work is properly cited, appropriate credit is given, any changes made indicated, and the use is non-commercial. See: http://creativecommons.org/ licenses/by-nc/4.0/

(c) Author(s) (or their employer(s)) 2019. Re-use permitted under CC BY-NC. No commercial re-use. See rights and permissions. Published by BMJ.

BMJ Open 2019;9:e027402corr1. doi:10.1136/bmjopen-2018-027402corr1

A) Check for updates 
Correction: Strategies occupational therapists employ to

facilitate work-related transitions for persons with hand injuries: a study protocol for a scoping review

Uys ME, Buchanan H, Van Niekerk L. Strategies occupational therapists employ to facilitate work-related transitions for persons with hand injuries: a study protocol for a scoping review. BMJ Open 2019;9:e027402. doi: 10.1136/bmjopen-2018-027402

This article was previously published with incomplete information in the funding section. The updated funding is below:

This work was supported by the National Research Foundation of South Africa (GRANT NUMBER: TTK160525166179). Opinions expressed and conclusions arrived at, are those of the authors and are not necessarily to be attributed to the NRF.

Open access This is an open access article distributed in accordance with the Creative Commons Attribution Non Commercial (CC BY-NC 4.0) license, which permits others to distribute, remix, adapt, build upon this work non-commercially, and license their derivative works on different terms, provided the original work is properly cited, appropriate credit is given, any changes made indicated, and the use is non-commercial. See: http://creativecommons.org/licenses/by-nc/4.0/

(c) Author(s) (or their employer(s)) 2020. Re-use permitted under CC BY-NC. No commercial re-use. See rights and permissions. Published by BMJ.

BMJ Open 2020;10:e027402corr2. doi:10.1136/bmjopen-2018-027402corr2

Check for updates 